\title{
The Association of Hearing Impairment and Its Severity with Physical and Mental Health among Chinese Adults
}

Xin Ye

Peking University https://orcid.org/0000-0002-8429-0900

Dawei Zhu

Peking University

Siyuan Chen

Peking University

Ping He ( $\nabla$ phe@pku.edu.cn )

https://orcid.org/0000-0001-5040-5012

\section{Research}

Keywords: Hearing Impairment, Severity, Chronic Diseases, ADLs, IADLs, Depressive Symptoms

Posted Date: February 3rd, 2020

DOI: https://doi.org/10.21203/rs.2.22440/v1

License: (c) (i) This work is licensed under a Creative Commons Attribution 4.0 International License. Read Full License

Version of Record: A version of this preprint was published at Health and Quality of Life Outcomes on May 26th, 2020. See the published version at https://doi.org/10.1186/s12955-020-01417-w. 


\section{Abstract}

Background: Hearing is one of the basic means of perception and communication, which is closely related with quality of life. However, current studies on hearing impairment and multiple health outcomes are quite limited and most of them are conducted in developed countries. Therefore, we aimed to explore the association between hearing impairment and its severity with physical and mental health among Chinese adults, and to gain further insight into hearing and health researches.

Methods: We obtained data from two sources: (1) China Health and Retirement Longitudinal Study (CHARLS) 2011, 2013 , and 2015, including nationally representative 24,689 adults. Hearing impairment was measured by asking whether they had hearing problems; and (2) Hearing Survey 2019, collected by a survey conducted in Shandong Province of China, including 430 participants. The severity of hearing impairment was identified by pure tone average of hearing thresholds at $0.5,1,2$, and $4 \mathrm{kHz}$.

Results: In CHARLS Baseline 2011, 1569 (8.93\%) participants suffer from hearing impairment. Hearing-impaired individuals are more likely to have chronic diseases, impaired ADLs, impaired IADLs and depressive symptoms. For 430 hearing-impaired participants in Hearing Survey $2019,28.60 \%, 36.52 \%$ and $34.88 \%$ of them have moderate, severe and profound hearing impairment, respectively. As the severity of hearing impairment increases, individuals are more likely to have impaired ADLs, impaired IADLs and depressive symptoms.

Conclusions: Hearing impairment and its severity are closely related to multiple physical and mental health outcomes among Chinese adults. Actions should be taken to prevent and treat hearing impairment, so as to improve people's health and well-being.

\section{Introduction}

Hearing impairment is one of the most common sensory dysfunctions, which adds to the burden of physical and mental health [1] and affects people's health extensively [2]. Empirical studies have shown that, hearing impairment brings about lower quality of life, including more comorbidity chronic diseases [3], impaired activities of daily living (ADLs) and instrumental activities of daily living (IADLs) $[4,5]$ as well as adverse mental health such as depression [1, 6]. The mechanism underlying may be that, hearing impairment can hinder information exchange and social participation, which further impairs active body function, increases psychological burden, and affects people's health $[4,5]$.

What's more, the risk of hearing impairment rises rapidly with age, so it is becoming an increasingly serious public health problem [7]. According to the Global Burden of Disease (GBD) 2015 study, half a billion people suffered from disabling hearing impairment (pure tone average of $35 \mathrm{~dB}$ or worse) worldwide [8]. In the United States, nearly twothirds of people over 70 suffered from hearing impairment [8]. In China, according to the Second National Sample Survey on Disability in 2006, the prevalence rate of hearing disability (moderate hearing impairment and above) was about $11 \%$ among the elderly over 60 [9], ranking top among six categories of disability (hearing, visual, speech, physical, intellectual and mental disabilities) [10]. In this context, it is imperative to conduct a study on the association between hearing impairment and health outcomes.

However, current studies on this topic are very limited and most of them are conducted in developed countries. It has been shown that hearing impairment brings about poor quality of life in community-dwelling older adults [11], presenting in part as poor physical health and psychological health in developed countries like the U.S. [4, 12], Australia [13, 14], Sweden [15], Finland [12], and Japan [16]. People with hearing impairment are more likely to have 
chronic diseases [17]. They need more assistance in activities of daily living [18] and have more chances to get affective mood disorders [19]. Only one study in Thailand, a middle-income country in Asia, showed that hearing impairment was associated with poor self-assessed health and psychological health among university adults [20]. And studies on the impact of hearing impairment mainly focused on single dimension of health, either physical functions $[4,5]$ or mental diseases $[1,6]$. Therefore, it is essential to further investigate the association of hearing impairment and multiple health outcomes, including physical and mental health.

Our study based on two surveys, the nationally representative data from China Health and Retirement Longitudinal Study (CHARLS) in 2011, 2013 and 2015 and the latest hearing survey in 2019, aims to gain a comprehensive understanding of the association between hearing impairment and multiple health outcomes in Chinese adults. This study will draw wide public attention to hearing impairment, as well as turning to early prevention and treatment.

\section{Methods}

\section{Study Sample and Population}

We obtained information from the CHARLS 2011, 2013, 2015 and Hearing Survey 2019, eying on the communitydwelling Chinese adults aged 18 years old or above. CHARLS is a long-term tracking project, with its baseline survey conducted in 2011 and follow-up surveys in 2013 and 2015 [21]. CHARLS adopted the method of PPS (Probability Proportional to Size) and sampling from maps in 450 villages/resident committees, 150 counties/districts and 28 provinces [22], and combined detailed socioeconomic data with high-quality health data, in order to address challenges of China's aging problem. After data pooling, collating and cleaning, we got the nationally representative 24,689 samples from CHARLS 2011, 2013, and 2015, with 17,561 samples in baseline 2011.

In order to investigate the association between the severity of hearing impairment and physical and mental health outcomes, we conducted a randomized controlled trial of adults with moderate hearing impairment and above (4 frequencies $(0.5,1,2,4 \mathrm{kHz})>40 \mathrm{~dB})$, and with no hearing aids use at baseline in Linyi City, Shandong Province of China. We provided the treatment group with hearing aids and traced changes in health outcomes for those with and without hearing aids. According to the list provided by the hearing center of Linyi Disabled Persons' Federation, 500 people were randomly selected. The survey was implemented in July 2019 and included 430 valid questionnaires.

\section{Independent variables: hearing impairment and its severity}

In CHARLS 2011, 2013 and 2015, hearing status was derived by asking whether respondents have hearing problems or not. The result is a subjective answer "yes" or "no". Prior studies have proved that a single-item question about an individual's hearing ability is moderately useful and valid to assess hearing and can be used for a population-based study $[23,24]$.

Hearing Survey 2019 measures hearing status by conducting pure-tone average (PTA) at the thresholds of $0.5,1,2$, and $4 \mathrm{k} \mathrm{Hz}$. According to the classification by World Health Organization, we defined those as moderate hearing impairment if PTA $>40 \mathrm{~dB}$ and PTA $\leq 60 \mathrm{~dB}$, severe hearing impairment if PTA $>60 \mathrm{~dB}$ and PTA $\leq 80 \mathrm{~dB}$, and profound hearing impairment if PTA > $80 \mathrm{~dB}[25]$.

\section{Outcome variables: physical and mental health status}

In both CHARLS and Hearing Survey, we incorporated several variables to measure health status. Physical health was measured by whether they had chronic diseases [26], impaired ADLs [27] and impaired IADLs [28]; Mental health was measured by whether they had depressive symptoms [29]. 
(1) Chronic diseases: Individuals were asked whether they had been diagnosed with chronic diseases, including hypertension, dyslipidemia, diabetes, cancer, chronic lung disease, liver disease, heart attack, stroke, kidney disease, digestive disease, psychiatric problems, memory-related disease, arthritis or asthma. If individuals reported having at least one of these chronic diseases, we defined them as having chronic diseases.

(2) ADLs: Individuals were asked whether they had any difficulty with activities of daily living, including dressing, bathing or showering, eating, getting into or out of bed, using the toilet, or controlling urination and defecation. Impaired ADLs was defined as reporting some difficulty with any of the activity or could not do the activity [30].

(3) IADLs: Individuals were asked whether they had any difficulty with instrumental activities of daily living, including doing household chores, preparing hot meals, shopping for groceries, making phone calls, taking medications, or managing money. Impaired IADLs was defined as reporting some difficulty with any of the activity or could not do the activity [30].

(4) Depressive symptoms: Both surveys applied the screening tool Center for Epidemiologic Studies Depression Scale-10 items (CES-D-10) to detect depressive symptoms [31]. A cut-off score of 10 on the CES-D-10 was identified as optimal to identify individuals at risk of depressive symptoms [32].

\section{Covariates}

Covariates include age (continuous variable), gender (male or female), residency (rural or urban), and educational attainment (illiterate, finishing primary school, finishing middle school and above).

\section{Statistical Analyses}

Descriptive analyses were used to present sample characteristics and hearing status. We used analysis of Variance (ANOVA) and the Chi-square test to compare characteristics between different hearing impairment categories. Logistic regression models and marginal effects were employed to predict the probabilities of having chronic diseases, impaired ADLs, impaired IADLs, and depressive symptoms with changes in hearing status while potential confounders were controlled [33]. The software Stata version 14.0 for Mac was utilized for statistical analyses. All hypothesis tests were two-sided, with a P-value less than 0.05 considered statistically significant.

\section{Results}

\section{Participants' characteristics}

The characteristics of CHARLS Baseline 2011 are shown in Table 1. It is found that the mean age of participants is 58.55 years old, with $47.92 \%$ male, $45.45 \%$ illiterate, $21.11 \%$ finishing only primary school and $33.44 \%$ with the degree of middle school and above. 1569 (8.93\%) participants suffer from hearing impairment. Compared to those with no hearing impairment, participants with hearing impairment tend to be older, female, and less educated. In terms of health status, participants with hearing impairment are more likely to have chronic diseases, impaired ADLs, impaired IADLs, and depressive symptoms. Table 1 shows more detailed features for participants in CHARLS Baseline 2011. 
Table 1

Descriptive Characteristics of Study Participants from Baseline CHARLS $2011(\mathrm{~N}=17,561)$

\begin{tabular}{|c|c|c|c|c|c|c|c|}
\hline \multirow[t]{2}{*}{ Characteristic } & \multicolumn{2}{|l|}{ All } & \multicolumn{2}{|c|}{ No Hearing Impairment } & \multicolumn{2}{|c|}{ Hearing Impairment } & \multirow[t]{2}{*}{ p Value } \\
\hline & $\mathrm{n}$ & $\%$ & $\mathrm{n}$ & $\%$ & $\mathrm{n}$ & $\%$ & \\
\hline $\mathrm{N}$ & 17,561 & 100.00 & 15,992 & 91.07 & 1,569 & 8.93 & \\
\hline Age (S.E.) & \multicolumn{2}{|c|}{$58.55(0.08)$} & \multicolumn{2}{|c|}{$57.81(0.08)$} & \multicolumn{2}{|c|}{$66.10(0.29)$} & $<0.001$ \\
\hline \multicolumn{7}{|l|}{ Gender } & 0.026 \\
\hline Male & 8,416 & 47.92 & 7,622 & 43.40 & 794 & 4.52 & \\
\hline Female & 9,145 & 52.08 & 8,370 & 47.66 & 775 & 4.41 & \\
\hline \multicolumn{7}{|l|}{ Education } & $<0.001$ \\
\hline Illiterate & 7,982 & 45.45 & 6,956 & 39.61 & 1,026 & 5.84 & \\
\hline Primary School & 3,706 & 21.11 & 3,421 & 19.48 & 285 & 1.62 & \\
\hline Middle School and above & 5,873 & 33.44 & 5,615 & 31.97 & 258 & 1.47 & \\
\hline \multicolumn{7}{|l|}{ Chronic Diseases } & $<0.001$ \\
\hline 0 & 5,424 & 30.90 & 5,092 & 29.00 & 332 & 1.89 & \\
\hline$\geq 1$ & 12,132 & 69.10 & 10,896 & 62.06 & 1,236 & 7.04 & \\
\hline \multicolumn{7}{|l|}{ ADLs } & $<0.001$ \\
\hline No-impaired & 14,464 & 83.40 & 13,448 & 77.54 & 1,016 & 5.86 & \\
\hline Impaired & 2,879 & 16.60 & 2,342 & 13.50 & 537 & 3.10 & \\
\hline \multicolumn{7}{|l|}{ IADLs } & $<0.001$ \\
\hline No-impaired & 13,783 & 78.63 & 12,943 & 73.84 & 840 & 4.79 & \\
\hline Impaired & 3,745 & 21.37 & 3,020 & 17.23 & 725 & 4.14 & \\
\hline \multicolumn{7}{|l|}{ Depressive Symptoms } & $<0.001$ \\
\hline No & 10,081 & 62.82 & 9,452 & 58.90 & 629 & 3.92 & \\
\hline Yes & 5,967 & 37.18 & 5,252 & 32.73 & 715 & 4.46 & \\
\hline \multicolumn{8}{|c|}{ ADLs = activities of daily living; IADLs = instrumental activities of daily living. } \\
\hline \multicolumn{8}{|c|}{${ }^{*} P<0.05,{ }^{* *} P<0.01 \nabla^{* \star *} P<0.001$} \\
\hline
\end{tabular}

The characteristics of Hearing Survey 2019 for 430 participants are shown in Table 2. The mean age of participants is 63.57 years, with $68.37 \%$ male, $42.33 \%$ illiterate, $33.25 \%$ finishing only primary school and $24.42 \%$ with the degree of middle school and above. In terms of hearing severity, 123 (28.60\%) participants have moderate hearing impairment, 157 (36.52\%) with severe hearing impairment, and 150 (34.88\%) with profound hearing impairment. Participants with more severe hearing impairment tend to be older, with chronic diseases, and depressive symptoms. Table 2 shows more detailed features for participants in 2015. 
Table 2

Descriptive Characteristics of Study Participants from Hearing Survey $2019(N=430)$

\begin{tabular}{|c|c|c|c|c|c|c|c|c|c|}
\hline \multirow[t]{2}{*}{ Characteristic } & \multicolumn{2}{|l|}{ All } & \multicolumn{2}{|c|}{$\begin{array}{l}\text { Moderate Hearing } \\
\text { Impairment }\end{array}$} & \multicolumn{2}{|c|}{$\begin{array}{l}\text { Severe Hearing } \\
\text { Impairment }\end{array}$} & \multicolumn{2}{|c|}{$\begin{array}{l}\text { Profound Hearing } \\
\text { Impairment }\end{array}$} & \multirow[t]{2}{*}{$\begin{array}{l}\mathrm{p} \\
\text { Value }\end{array}$} \\
\hline & $\mathbf{n}$ & $\%$ & $\mathbf{n}$ & $\%$ & $\mathbf{n}$ & $\%$ & $\mathbf{n}$ & $\%$ & \\
\hline $\mathrm{N}$ & 430 & 100.00 & 123 & 28.60 & 157 & 36.52 & 150 & 34.88 & \\
\hline Age (S.E.) & \multicolumn{2}{|c|}{$63.57(0.77)$} & \multicolumn{2}{|c|}{$66.21(1.21)$} & \multicolumn{2}{|c|}{$66.41(1.15)$} & \multicolumn{2}{|c|}{$58.44(1.50)$} & $\begin{array}{l}< \\
0.001\end{array}$ \\
\hline Gender & & & & & & & & & 0.770 \\
\hline Male & 294 & 68.37 & 87 & 20.23 & 107 & 24.88 & 100 & 23.26 & \\
\hline Female & 136 & 31.63 & 36 & 8.37 & 50 & 11.63 & 50 & 11.63 & \\
\hline Education & & & & & & & & & 0.118 \\
\hline Illiterate & 182 & 42.33 & 53 & 12.33 & 68 & 15.81 & 61 & 14.19 & \\
\hline Primary School & 143 & 33.25 & 34 & 7.91 & 61 & 14.19 & 48 & 11.16 & \\
\hline $\begin{array}{l}\text { Middle School } \\
\text { and above }\end{array}$ & 105 & 24.42 & 36 & 8.37 & 28 & 6.51 & 41 & 9.53 & \\
\hline Chronic Diseases & & & & & & & & & 0.016 \\
\hline 0 & 145 & 33.72 & 36 & 8.37 & 45 & 10.47 & 64 & 14.88 & \\
\hline$\geq 1$ & 285 & 66.28 & 87 & 20.23 & 112 & 26.05 & 86 & 20.00 & \\
\hline ADLs & & & & & & & & & 0.074 \\
\hline No-impaired & 343 & 79.77 & 106 & 24.65 & 118 & 27.44 & 119 & 27.67 & \\
\hline Impaired & 87 & 20.23 & 17 & 3.95 & 39 & 9.07 & 31 & 7.21 & \\
\hline \multicolumn{10}{|l|}{ IADLs } \\
\hline No-impaired & 155 & 36.05 & 54 & 12.56 & 54 & 12.56 & 47 & 10.93 & 0.085 \\
\hline Impaired & 275 & 63.95 & 69 & 16.05 & 103 & 23.95 & 103 & 23.95 & \\
\hline $\begin{array}{l}\text { Depressive } \\
\text { Symptoms }\end{array}$ & & & & & & & & & 0.010 \\
\hline No & 261 & 60.70 & 86 & 20.00 & 97 & 22.56 & 78 & 18.14 & \\
\hline Yes & 169 & 39.30 & 37 & 8.60 & 60 & 13.95 & 72 & 16.74 & \\
\hline
\end{tabular}

\section{The association between hearing impairment and multiple health outcomes}


Table 3 shows hearing impairment and its severity with the prevalence and odd ratio of having chronic diseases, impaired ADLs, impaired IADLs and depressive symptoms. We can see that $64 \%-82 \%$ of respondents report having chronic diseases. $30 \%-48 \%$ have depressive symptoms. Their physical functioning measured by ADLs and IADLs is relatively better, with only $13 \%-26 \%$ reporting impaired ADLs and $20 \%-72 \%$ reporting impaired IADLs.

Table 3

Prevalence and Odds Ratio of Chronic Diseases, Impaired ADLs, IADLs, and Depressive Symptoms by Hearing Status

\begin{tabular}{|c|c|c|c|c|c|c|c|c|}
\hline \multirow[t]{2}{*}{$\begin{array}{l}\text { Hearing } \\
\text { Status }\end{array}$} & \multicolumn{2}{|c|}{ Chronic Diseases } & \multicolumn{2}{|c|}{ Impaired ADLs } & \multicolumn{2}{|c|}{ Impaired IADLs } & \multicolumn{2}{|l|}{$\begin{array}{l}\text { Depressive } \\
\text { Symptoms }\end{array}$} \\
\hline & $\begin{array}{l}\text { Prevalence } \\
(95 \% \mathrm{Cl})\end{array}$ & $\begin{array}{l}\text { OR } \\
(95 \% \mathrm{Cl})\end{array}$ & $\begin{array}{l}\text { Prevalence } \\
(95 \% \mathrm{Cl})\end{array}$ & $\begin{array}{l}\text { OR } \\
(95 \% \mathrm{Cl})\end{array}$ & $\begin{array}{l}\text { Prevalence } \\
(95 \% \mathrm{Cl})\end{array}$ & $\begin{array}{l}\text { OR } \\
(95 \% \mathrm{Cl})\end{array}$ & $\begin{array}{l}\text { Prevalence } \\
(95 \% \mathrm{Cl})\end{array}$ & $\begin{array}{l}\text { OR } \\
(95 \% \mathrm{Cl})\end{array}$ \\
\hline \multicolumn{9}{|l|}{$\begin{array}{l}\text { CHARLS } \\
2015(\mathrm{~N}= \\
18,763)\end{array}$} \\
\hline \multicolumn{9}{|l|}{$\begin{array}{l}\text { Hearing } \\
\text { Status }\end{array}$} \\
\hline $\begin{array}{l}\text { No Hearing } \\
\text { Impairment } \\
\text { (Reference } \\
\text { Group) }\end{array}$ & $\begin{array}{l}0.74 \\
(0.73- \\
0.74)\end{array}$ & 1.00 & $\begin{array}{l}0.16 \\
(0.16- \\
0.17)\end{array}$ & 1.00 & $\begin{array}{l}0.20 \\
(0.20- \\
0.21)\end{array}$ & 1.00 & $\begin{array}{l}0.32 \\
(0.32- \\
0.33)\end{array}$ & 1.00 \\
\hline $\begin{array}{l}\text { Having } \\
\text { Hearing } \\
\text { Impairment }\end{array}$ & $\begin{array}{l}0.82 \\
(0.81- \\
0.83)\end{array}$ & $\begin{array}{l}1.62^{\star \star \star} \\
(1.51- \\
1.73)\end{array}$ & $\begin{array}{l}0.26 \\
(0.25- \\
0.27)\end{array}$ & $\begin{array}{l}1.90^{\star \star \star} \\
(1.79- \\
2.02)\end{array}$ & $\begin{array}{l}0.35 \\
(0.34- \\
0.36)\end{array}$ & $\begin{array}{l}2.33^{\star \star \star} \\
(2.21- \\
2.47)\end{array}$ & $\begin{array}{l}0.43 \\
(0.42- \\
0.44)\end{array}$ & $\begin{array}{l}1.62^{\star \star \star} \\
(1.54- \\
1.72)\end{array}$ \\
\hline \multicolumn{9}{|l|}{$\begin{array}{l}\text { Hearing } \\
\text { Data }(\mathrm{N}= \\
430)\end{array}$} \\
\hline \multicolumn{9}{|l|}{$\begin{array}{l}\text { Hearing } \\
\text { Status }\end{array}$} \\
\hline $\begin{array}{l}\text { Moderate } \\
\text { Hearing } \\
\text { Impairment } \\
\text { (Reference } \\
\text { Group) }\end{array}$ & $\begin{array}{l}0.67 \\
(0.60- \\
0.75)\end{array}$ & 1.00 & $\begin{array}{l}0.13 \\
(0.07- \\
0.19)\end{array}$ & 1.00 & $\begin{array}{l}0.55 \\
(0.46- \\
0.63)\end{array}$ & 1.00 & $\begin{array}{l}0.30 \\
(0.22- \\
0.38)\end{array}$ & 1.00 \\
\hline $\begin{array}{l}\text { Severe } \\
\text { Hearing } \\
\text { Impairment }\end{array}$ & $\begin{array}{l}0.68 \\
(0.61- \\
0.75)\end{array}$ & $\begin{array}{l}1.02 \\
(0.58- \\
1.81)\end{array}$ & $\begin{array}{l}0.23 \\
(0.17- \\
0.30)\end{array}$ & $\begin{array}{l}2.13^{*} \\
(1.12- \\
4.06)\end{array}$ & $\begin{array}{l}0.63 \\
(0.56- \\
0.70)\end{array}$ & $\begin{array}{l}1.46 \\
(0.88- \\
2.42)\end{array}$ & $\begin{array}{l}0.38 \\
(0.30- \\
0.46)\end{array}$ & $\begin{array}{l}1.45 \\
(0.88- \\
2.41)\end{array}$ \\
\hline $\begin{array}{l}\text { Profound } \\
\text { Hearing } \\
\text { Impairment }\end{array}$ & $\begin{array}{l}0.64 \\
(0.57- \\
0.71)\end{array}$ & $\begin{array}{l}0.82 \\
(0.47- \\
1.45)\end{array}$ & $\begin{array}{l}0.24 \\
(0.17- \\
0.31)\end{array}$ & $\begin{array}{l}2.16^{*} \\
(1.10- \\
4.22)\end{array}$ & $\begin{array}{l}0.72 \\
(0.65- \\
0.79)\end{array}$ & $\begin{array}{l}2.30^{\star *} \\
(1.34- \\
3.94)\end{array}$ & $\begin{array}{l}0.48 \\
(0.40- \\
0.57)\end{array}$ & $\begin{array}{l}2.22^{\star \star} \\
(1.33- \\
3.72)\end{array}$ \\
\hline \multicolumn{9}{|c|}{$\begin{array}{l}\text { Component scores are adjusted for age, sex, and education. The means are given first, followed parenthetically by } \\
\text { confidence intervals. ADLs = activities of daily living; IADLs = instrumental activities of daily living; OR = Odd } \\
\text { Ratios; } \mathrm{Cl}=\text { Confidence Intervals. }\end{array}$} \\
\hline \multicolumn{9}{|c|}{${ }^{*} \mathrm{P}<0.05,{ }^{* \star} \mathrm{P}<0.01 \rrbracket^{\star \star \star} \mathrm{P}<0.001$} \\
\hline
\end{tabular}

Results from CHARLS 2015 indicate that, hearing impairment significantly relates to the risk of physical and mental health. Compared with those having no hearing impairment, the prevalence of chronic diseases $(\mathrm{OR}=1.62,95 \% \mathrm{Cl}=$ 
1.51-1.73), impaired ADLs $(\mathrm{OR}=1.90,95 \% \mathrm{Cl}=1.79-2.02)$, impaired IADLs $(\mathrm{OR}=2.33,95 \% \mathrm{Cl}=2.21-2.47)$ and depressive symptoms $(\mathrm{OR}=1.62,95 \% \mathrm{Cl}=1.54-1.72)$ increase if individuals have self-reported hearing impairment.

\section{The association between the severity of hearing impairment and multiple health outcomes}

Results from Hearing Survey 2019 indicate that, different levels of hearing impairment severity are linked to different risks of having impaired ADLs, IADLs, and depressive symptoms.

To be exact, for those with severe and profound hearing impairment, the prevalence of impaired ADLs is significantly larger than the reference group (moderate hearing impairment) $(\mathrm{OR}=2.13,95 \% \mathrm{Cl}=1.12-4.06 ; \mathrm{OR}=2.16,95 \% \mathrm{Cl}=$ $1.10-4.22)$. For those with profound hearing impairment, the prevalence of impaired IADLs $(\mathrm{OR}=2.30,95 \% \mathrm{Cl}=1.34-$ $3.94)$ and depressive symptoms $(\mathrm{OR}=2.22,95 \% \mathrm{Cl}=1.33-3.72)$ is significantly larger than the group of moderate hearing impairment.

While groups with moderate and severe hearing impairments show no differences in the prevalence of impaired IADLs (OR $=1.46,95 \% \mathrm{Cl}=0.88-2.42)$ and depressive symptoms $(\mathrm{OR}=1.45,95 \% \mathrm{Cl}=0.88-2.41)$. And among groups with moderate to profound hearing impairment, the prevalence of chronic diseases does not show large differences $(\mathrm{OR}=1.02,95 \% \mathrm{Cl}=0.58-1.81 ; \mathrm{OR}=0.82,95 \% \mathrm{Cl}=0.47-1.45)$.

\section{Discussion}

With the population aging, an increasing number of people are living with hearing impairment, especially during their later-life years. It is said that more than $90 \%$ of hearing impairments in the world are age-related [34] and most of them are irreversible [35]. On the other hand, hearing impairment often has a slow onset and progressive deterioration [36], which results in detection difficulty unless checked by accurate pure tone measurement. In addition, a large proportion of people regard hearing impairment as a natural process of aging which can be ignorable, so hearing impairment has not yet received enough attention as it deserves [37]. All these factors result in hearing impairment an unrecognized and under-treated health problem [36].

What we have found among hearing-impaired adults in China is generally consistent with previous studies about the effects of hearing impairment on people's physical and mental health. People with more severe hearing impairment tend to be older [38], female [4], and less educated [39]. Hearing impairment has been proved to correlate with more chronic diseases [17]. And with the deterioration of hearing impairment, people are more likely to have poorer body functions measured by activities of daily living (ADLs) and instrumental activities of daily living (IADLs) [4, 5]. In addition, hearing impairment can also lead to depressive symptoms, such as sadness, hopelessness, helplessness [40], and exacerbating the decline in individuals' psychosocial well-being [41].

Our results further demonstrated the association of different severity of hearing impairment with their physical and mental health. The prevalence of impaired ADLs shows an elevated increase for those with severe to profound hearing impairment, compared with moderate hearing impairment. For those with profound hearing impairment, the prevalence of impaired IADLs and depressive symptoms are much higher than those with moderate hearing impairment. The underlying mechanism may be that, ADLs measures basic functions in daily activities and IADLs measures functions in more subtle activities, so hearing impairment may be more related to the decline in certain brain structures that control these functions [4]. And hearing impairment inevitably brings about communication barriers, thus the more probability of falling into depression is conceivable [40]. However, the prevalence of chronic 
diseases does not show significant differences within groups of severe to profound hearing impairment, which may due to the limited sample size or the selection of reference group.

Since hearing impairment can be difficult to detect and cure, and is closely related to health, it is imperative to raise awareness and take effective measures. For newborns, the screening and prevention of hearing impairment should be taken as early as possible. For those with hearing impairment, especially with moderate and above hearing impairment, it is necessary to provide rehabilitative devices to compensate for the loss of functions, such as wearing hearing aids [42]. It has been proved that people who use hearing aids reported better self-care, lower levels of depression, and better overall health [43]. However, due to the high price of hearing aids, the accessibility and utilization rate are relatively low worldwide [44]. Our findings highlight the need to improve the health of the hearingimpaired population through early detection and making auditory rehabilitation devices such as hearing aids more accessible and affordable.

The limitations of our study are that, first, some hearing and health variables are determined by participants' selfreported data, which may bring some bias. Second, although some confounders have been controlled, other undetectable confounders may also affect the results. The strengths lie in that, first of all, our study focuses on the association between hearing impairment and health outcomes in China, which is a relatively unexplored and prospective topic in developing countries. Second, we apply multiple physical and mental health outcomes to demonstrate the harm of hearing impairment from different perspectives. Third, we not only use three years of CHARLS data to elucidate the complex interplay between hearing impairment and health, but take a step further to investigate different severity of hearing impairment. Finally, we combine both self-reported hearing status and objective measures of hearing using pure-tone tests, which can act as more profound and compelling evidence.

\section{Conclusions}

The high prevalence and increasing severity of hearing impairment have been a tendency in the aging society. Hearing impairment and its severity are closely correlated with physical and mental health in Chinese adults. Immediate actions should be taken to prevent and treat hearing impairment, so as to improve their health and wellbeing of hearing-impaired people.

\section{Declarations}

\section{Abbreviations}

CHARLS: China Health and Retirement Longitudinal Study; ADLs = activities of daily living; IADLs = instrumental activities of daily living; $\mathrm{OR}=$ Odd Ratios; $\mathrm{Cl}$ = Confidence Intervals; ANOVA: analysis of variance.

\section{Ethics approval and consent to participate}

The ethics application for collecting data on human subjects was approved and updated annually by Peking University's Institutional Review Board. All participants provided written informed consent.

\section{Consent for publication}

Not applicable.

\section{Availability of data and materials}


The data supporting the conclusion of this article are includes within the article. Any queries regarding these data may be directed to the corresponding author.

\section{Competing interests}

The authors declare that they have no competing interests.

\section{Funding}

This study was supported by National Natural Science Foundation of China (grant no. 71874005).

\section{Authors' contributions}

XY analyzed and interpreted the data. SC helped collect the data. DZ and PH provided statistical analysis and critical revision. All authors read and approved the final manuscript.

\section{Acknowledgements}

We would like to thank all participants for their time. All authors approved the final manuscript and have participated sufficiently in the work to take public responsibility for appropriate portions of the content

\section{References}

1. West JS. Hearing impairment, social support, and depressive symptoms among U.S. adults: A test of the stress process paradigm. Soc Sci Med. 2017;192:94-101.

2. World Health Organization. Deafness and Hearing Loss 2019 [Available from: https://www.who.int/newsroom/fact-sheets/detail/deafness-and-hearing-loss.

3. Van den Akker M, Buntinx F, Metsemakers JF, Roos S, Knottnerus JA. Multimorbidity in general practice: prevalence, incidence, and determinants of co-occurring chronic and recurrent diseases. J Clin Epidemiol. 1998;51(5):367-75.

4. Dalton DS, Cruickshanks KJ, Klein BE, Klein R, Wiley TL, Nondahl DM. The impact of hearing loss on quality of life in older adults. Gerontologist. 2003;43(5):661-8.

5. Arlinger S. Negative consequences of uncorrected hearing loss--a review. Int J Audiol. 2003;42 Suppl 2:2s17-20.

6. Kramer SE, Kapteyn TS, Kuik DJ, Deeg DJ. The association of hearing impairment and chronic diseases with psychosocial health status in older age. Journal of aging and health. 2002;14(1):122-37.

7. Stevens G, Flaxman S, Brunskill E, Mascarenhas M, Mathers CD, Finucane M. Global and regional hearing impairment prevalence: an analysis of 42 studies in 29 countries. Eur J Public Health. 2013;23(1):146-52.

8. GBD 2015 Disease and Injury Incidence and Prevalence Collaborators. Global, regional, and national incidence, prevalence, and years lived with disability for 310 diseases and injuries, 1990-2015: a systematic analysis for the Global Burden of Disease Study 2015. Lancet. 2016;388(10053):1545-602.

9. National Bureau of Statistics of the People's Republic of China. The main data bulletin of the second national sampling survey for the disabled (Number 2) [Available from: http://www.gov.cn/fwxx/cjr/content_1308391.htm.

10. Zheng X. Research on disability prevention in China: Huaxia Press; 2008. 
11. Tseng YC, Liu SH, Lou MF, Huang GS. Quality of life in older adults with sensory impairments: a systematic review. Quality of Life Research An International Journal of Quality of Life Aspects of Treatment Care \& Rehabilitation. 2018;27(8):1957-71.

12. Polku H, Mikkola TM, Rantakokko M, Portegijs E, Törmäkangas $T$, Rantanen $T$, et al. Hearing and quality of life among community-dwelling older adults. The Journals of Gerontology: Series B. 2016;73(3):543-52.

13. Hogan A, K. OL, Miller P, Kendig H. The health impact of a hearing disability on older people in Australia. J Aging Health. 2009;21(8):1098-111.

14. Chia EM, Wang JJ, Rochtchina E, Cumming RR, Newall P, Mitchell P. Hearing impairment and health-related quality of life: the Blue Mountains Hearing Study. Ear and hearing. 2007;28(2):187-95.

15. Hallberg LR, Hallberg U, Kramer SE. Self-reported hearing difficulties, communication strategies and psychological general well-being (quality of life) in patients with acquired hearing impairment. Disability and rehabilitation. 2008;30(3):203-12.

16. Ishine M, Okumiya K, Matsubayashi K. A close association between hearing impairment and activities of daily living, depression, and quality of life in community-dwelling older people in Japan. Journal of the American Geriatrics Society. 2007;55(2):316-7.

17. Wilson D, S. X, Read P, Walsh P, Esterman A. Hearing loss-an underestimated public health problem. Aust J Public Health. 1992;16(3):282-6.

18. Wilson DH. Hearing in South Australia : disability, impairment and quality-of-life. 1997.

19. Ihara K. Depressive states and their correlates in elderly people living in a rural community. [Nippon kōshū eisei zasshi] Japanese journal of public health. 1993;40(2):85-94.

20. Yiengprugsawan V, Hogan A, Harley D, Seubsman SA, Sleigh AC. Epidemiological Associations of Hearing Impairment and Health Among a National Cohort of 87134 Adults in Thailand. Asia-Pacific Journal of Public Health. 2012;24(6):1013-22.

21. About CHARLS 2019 [Available from: http://charls.pku.edu.cn/pages/about/111/zh-cn.html.

22. China Health and Retirement Report 2019 [Available from:

http://charls.pku.edu.cn/Public/ashelf/public/uploads/document/public_documents/application/china-healthretirement-report.pdf.

23. Huddle MG, Deal JA, Swenor B, Genther DJ, Lin FR. Association Between Dual Sensory Impairment, Hospitalization, and Burden of Disease. J Am Geriatr Soc. 2016;64(8):1735-7.

24. Liu PL, Cohen HJ, Fillenbaum GG, Burchett BM, Whitson HE. Association of Co-Existing Impairments in Cognition and Self-Rated Vision and Hearing With Health Outcomes in Older Adults. Gerontol Geriatr Med. 2016;2.

25. World Health Organization. Grades of Hearing Impairment 2019 [Available from: https://www.who.int/pbd/deafness/hearing_impairment_grades/en/.

26. Bauer UE, Briss PA, Goodman RA, Bowman BA. Prevention of chronic disease in the 21st century: elimination of the leading preventable causes of premature death and disability in the USA. Lancet. 2014;384(9937):45-52.

27. Katz S, Ford AB, Moskowitz RW, Jackson BA, Jaffe MW. Studies of illness in the aged. The index of ADL: A standardized measure of biological and psychosocial function. Journal of the American Medical Association. 1963(185):94-9.

28. Lawton MP, Brody EM. Assessment of older people: self-maintaining and instrumental activities of daily living. The Gerontologist. 1969(9):179-86.

29. Kagee A, C. TA, Lund C, Tomlinson M. Screening for common mental disorders in low resource settings: reasons for caution and a way forward. International Health. 2012(5):11-4.

Page $11 / 12$ 
30. Dalton DS, Cruickshanks Kj Fau - Klein BEK, Klein Be Fau - Klein R, Klein R Fau - Wiley TL, Wiley TI Fau - Nondahl DM, Nondahl DM. The impact of hearing loss on quality of life in older adults. Gerontologist. 2003;43(5):661-8.

31. Andresen EM, A. MJ, Carter WB, Patrick DL. Screening for depression in well older adults: evaluation of a short form of the CES-D (Center for Epidemiologic Studies Depression Scale). Am J Prev Med. 1994;10(2):77-84.

32. Tomita A, Burns JK. Depression, disability and functional status among community-dwelling older adults in South Africa: evidence from the first South African National Income Dynamics Study. Int J Geriatr Psychiatry. 2013(28):1270-9.

33. Norton EC, Dowd BE, Maciejewski ML. Marginal effects-quantifying the effect of changes in risk factors in logistic regression models. Jama. 2019;321(13):1304-5.

34. Vos T, Allen C, Arora M, Barber RM, Bhutta ZA, Brown A, et al. Global, regional, and national incidence, prevalence, and years lived with disability for 310 diseases and injuries, 1990-2015: a systematic analysis for the Global Burden of Disease Study 2015. Lancet. 2016;388(10053):1545-602.

35. Arlinger S. Negative consequences of uncorrected hearing loss-a review. Int J Audiol. 2003;42:2S17-2S20.

36. Chew HS, Yeak S. Quality of life in patients with untreated age-related hearing loss. J Laryngol Otol. 2010;124(8):835-41.

37. Davis A, McMahon CM, Pichora-Fuller KM, Russ S, Lin F, Olusanya BO, et al. Aging and Hearing Health: The Lifecourse Approach. Gerontologist. 2016;56:S256-67.

38. Stevens G, Flaxman S Fau - Brunskill E, Brunskill E Fau - Mascarenhas M, Mascarenhas M Fau - Mathers CD, Mathers Cd Fau - Finucane M, Finucane M. Global and regional hearing impairment prevalence: an analysis of 42 studies in 29 countries. Eur J Public Health. 2013;23(1):146-52.

39. Stam M, Kostense P, Festen J, Kramer S. The relationship between hearing status and the participation in different categories of work: demographics. Work. 2013;46(2):207-19.

40. Knutson JF, Lansing CR. The relationship between communication problems and psychological difficulties in persons with profound acquired hearing loss. J Speech Hear Disord. 1990;55(4):656-64.

41. Pronk M, Deeg DJH, Smits C, Twisk JW, Tilburg TGv, Festen JM, et al. Hearing Loss in Older Persons:Does the Rate of Decline Affect Psychosocial Health? Journal of Aging and Health. 2014;26(5):703-23.

42. Nieman CL, Marrone N, Mamo SK, Betz J, Choi JS, Contrera KJ, et al. The Baltimore HEARS Pilot Study: An Affordable, Accessible, Community-Delivered Hearing Care Intervention. Gerontologist. 2017;57(6):1173-86.

43. Appollonio I, Carabellese C, Frattola L, Trabucchi M. Effects of sensory aids on the quality of life and mortality of elderly people: a multivariate analysis. Age and ageing. 1996;25(2):89.

44. Perez E, Edmonds BA. A systematic review of studies measuring and reporting hearing aid usage in older adults since 1999: a descriptive summary of measurement tools. PloS one. 2012;7(3):e31831. 